\title{
Distribution of Carnus hemapterus in a starling colony
}

\author{
András Liker, Márta Márkus, Ágnes Vozár, Eszter Zemankovics, and Lajos Rózsa
}

\begin{abstract}
The distribution of the haematophagous fly Carnus hemapterus among starling (Sturnus vulgaris) broods was investigated in a nest-box colony. Prevalence of infection was $94 \%$ among broods and $69 \%$ among individual nestlings, while median abundance was 54 flies per brood (range $0-284$ flies; $n=33$ ) and 8 flies per individual nestling (range 0-117 flies; $n=140$ ). Parasites exhibited an aggregated distribution among starling broods. Carnus hemapterus populations changed significantly during the development of nestlings: fly abundance increased rapidly after nestlings hatched, peaked 5-8 days after hatching, and decreased thereafter. The proportion of winged flies (assumed to be the transmissive form) and the proportion of male flies decreased with increasing nestling mass. Measures of within-colony spatial position of nests were not related to mean brood abundance, proportion of winged flies, or sex ratio of the flies. Parasite abundance did not correlate with mortality rate or growth rate of nestlings. In conclusion, nestling developmental stage was the only significant predictor of variation in $C$. hemapterus populations in this starling colony.
\end{abstract}

\begin{abstract}
Résumé : Nous avons étudié la répartition de la mouche hématophage Carnus hemapterus dans les couvées, au sein d'une colonie d'Étourneaux sansonnets (Sturnus vulgaris) dans des boîtes à nicher. La prévalence des infections atteignait $94 \%$ dans les couvées et $69 \%$ chez les oisillons au nid; l'abondance médiane était de 54 mouches par couvée (étendue 0-284 mouches; $n=33$ ) et de 8 mouches par oisillon (étendue 0-117 mouches; $n=140$ ). Les mouches avaient une répartition contagieuse parmi les couvées et les populations de $C$. hemapterus ont changé significativement au cours du développement des oisillons : l'abondance des mouches a augmenté rapidement après l'éclosion des oeufs, a atteint son maximum 5-8 jours après l'éclosion pour décliner par la suite. La proportion de mouches ailées (que l'on suppose être les vecteurs du parasitisme) et la proportion de mâles ont subi une diminution pendant l'augmentation de la masse des oisillons. La mesure de la position spatiale d'un nid au sein de la colonie n'était pas reliée à l'abondance moyenne dans la couvée, ni à la proportion d'individus ailés, ni au rapport mâles : femelles chez les mouches. L'abondance des parasites n'était pas associée à la mortalité ou au taux de croissance des oisillons. Le stade de développement des oisillons est donc le seul facteur de prédiction de la variation des populations de C. hemapterus dans cette colonie.
\end{abstract}

[Traduit par la Rédaction]

\section{Introduction}

Aggregation of avian hosts has often been found to increase the prevalence and intensity of infection by ectoparasites. For example, intraspecific comparisons have shown that individuals living in large breeding colonies harbour more parasites than those living in small ones or at solitary breeding sites (e.g., Hoogland and Sherman 1976; Duffy 1983; Møller 1987; Brown and Brown 1996; Davis and Brown 1999). Aggregation of host individuals usually varies within a colony, so spatial position of nests within a colony may also influence parasite prevalence and abundance. Central nests in a colony or nests with close neighbours should be more prone to colonisation by mobile ectoparasites from surrounding areas, making these breeding sites potentially costly. However, relatively few studies have tested whether spatial position of

Received May 1, 2000. Accepted January 15, 2001. Published on the NRC Research Press Web site on March 23, 2001.

A. Liker, ${ }^{1}$ M. Márkus, Á. Vozár, and E. Zemankovics. Department of Ecology, Faculty of Veterinary Science, Szent István University, P.O. Box 2, H-1400 Budapest, Hungary. L. Rózsa. Department of Zoology, University of Veszprém, P.O. Box 158, H-8201 Veszprém, Hungary.

${ }^{1}$ Corresponding author (e-mail: aliker@univet.hu). nests affects ectoparasite abundance, and the results of these studies are conflicting. For example, in cliff swallows (Hirundo pyrrhonota), the intensity of infection by the swallow bug (Oeciacus vicarius) decreased with increasing nearest neighbour distance but increased with distance from the colony centre. On the other hand, the intensity of infection by a presumably less mobile bird flea (Ceratophyllus celsus) was not related to any measure of spatial position of nests (Brown and Brown 1996). Abundance of fleas was also not related to the degree of nest isolation in house martins (Delichon urbica; Clarck and McNeil 1981). In colonies of European bee-eaters (Merops apiaster), louse abundance correlated negatively with internest distance (Hoi et al. 1998). Because ectoparasites often depress the reproductive success and survival of their avian hosts, their abundance and spatial distribution may affect the attractiveness of particular breeding sites, and may have substantial impacts on host population dynamics and social behaviour (Lehmann 1993; Møller 1993; Møller et al. 1993; Loye and Carroll 1995; Brown and Brown 1996).

In this study we investigated the distribution of a mobile ectoparasite, the haematophagous fly Carnus hemapterus (Nitzsch 1818, Diptera: Carnidae), among starling (Sturnus vulgaris) broods. Starlings are common Holarctic hole-nesting birds (ca. 70-80 g body mass) that prefer to breed colonially 
where nests sites are available at high densities, such as in nest-box colonies. Their nestlings spend about 17-21 days in the nest after hatching (Cramp and Perrins 1994), and are often heavily infected by the small (ca. $2 \mathrm{~mm}$ long) fly $C$. hemapterus. Although this fly is known to parasitise nestlings of more than 30 bird species in the Holarctic and other regions (Grimaldi 1997), its ecology and dispersive behaviour are poorly known. Adult flies probably feed on the blood of nestlings, although some authors suggest that they may also feed on oil secretions or particles of skin (Grimaldi 1997; Papp 1998). Females are assumed to lay their eggs in the host's nest, where the larvae live in nest debris and feed upon dead organic matter (Capelle and Whitworth 1973; Papp 1998). The pupae may overwinter in the debris, as suggested by a study of the barn owl (Tyto alba) in which more flies were present in nest boxes that had been occupied by owls during the previous year than in nest boxes that were previously unused (Roulin 1998). Adult flies appear in nests when the eggs of the hosts hatch, are initially winged and capable of flying, but lose their wings after locating a suitable host (Grimaldi 1997; Papp 1998). Since neither the adults nor the larvae have been found on adult birds, flies are assumed to colonise new hosts actively during the winged phase of their life cycle (Grimaldi 1997; Roulin 1998). In barn owls, the number of winged flies does not change during the first 40 days of the nestling period (although their proportion in the fly population decreases), thus dispersive forms may be present throughout the host's breeding cycle (Roulin 1998). It is not known whether new winged flies, which replace the ones that have shed their wings in a host's nest, are recruited from individuals emerging in the same nests or are immigrants (Roulin 1998). It is also not known how far a winged fly can disperse from a host's nest, and which sensory cues are used to locate suitable new hosts.

Our study has two purposes: to provide details of $C$. hemapterus populations living in starling nests and to investigate whether within-colony spatial position of nests affects the parasite burden of nestlings. First, we focus on $C$. hemapterus and describe the prevalence and intensity of infection and the variation in abundance in relation to host brood size, and investigate temporal changes in parasite numbers during nestling development. These temporal dynamics are interesting because species that are hosts of $C$. hemapterus may vary widely in the duration of their nestling period, i.e., the period when breeding conditions are suitable for the flies. For example, in barn owls, whose nestlings spend 2 months in the nest, the number of flies increases from hatching to the 28th day of chick age, and decreases afterwards, and flies disappear when the nestlings become feathered (Roulin 1998). Similarly, in American kestrels, Falco sparverius, most infections occur during the first 12 days of the nestling period, i.e., before the nestlings become feathered (Dawson and Bortolotti 1997). No comparable detailed study exists on the population dynamics of C. hemapterus in host species with a shorter rearing period, such as passerines. It may be expected that in a species with a much shorter nestling period, such as the starling, $C$. hemapterus exhibits a shorter period of activity, consequently the fly population may peak earlier than in owls and kestrels.

In the second part of the study we test whether variation in parasite burdens of nestlings is related to the variation in the within-colony spatial position of nests. Because winged $C$. hemapterus may actively seek new hosts around their natal nest (see above), the number of migrating flies is probably higher in places where nest-box density is high than in places where it is low. Thus, we predict that $(i)$ the abundance of flies, (ii) the proportion of winged flies, and (iii) the proportion of males are higher in central nests, or in nests with many close neighbours, than in nests in other spatial positions. Prediction iii is based on Hamilton's (1967) hypothesis of local mate competition, which predicts that females produce a higher number of male offspring at breeding sites where local competition for mates is stronger because of a higher rate of immigration. We also investigate whether fly abundance is related to some abiotic factors such as the exposure of a host's nest to wind and sunlight. For example, dispersing flies may avoid windy places, or may be attracted by nests situated in dense vegetation, where the larvae could develop in a humid environment (larvae are humidophilous; Papp 1998). Since nests situated near forest edge are more exposed to wind and sunlight than nests situated in the inner part of the forest, we investigate whether distance of nest boxes to forest edge is related to parasite abundance. Finally, we investigate whether growth and mortality rates of nestlings are related to parasite abundance.

\section{Methods}

The study was conducted in a starling colony located at the Dóra-farm Experimental Station of Szent István University, $30 \mathrm{~km}$ southeast of Budapest, in 1998. Fifty nest boxes were established in the early spring of 1997 . They were first used by starlings in that year. Nest material was removed after breeding and 3 nest boxes were eliminated in 1997, so 47 boxes were available in 1998, of which 42 were occupied by starlings. We changed the spatial position of half of the nest boxes before breeding in 1998. The nest boxes were placed on tree trunks in a forest within a $120 \times 60 \mathrm{~m}$ ( $0.7 \mathrm{ha})$ rectangular area. The nearest neighbour distance varied between 3 and $15 \mathrm{~m}$ (median $8 \mathrm{~m}$ ), and the distance of nest boxes from the geometric centre of the colony ranged from 1 to $65 \mathrm{~m}$ (median $28 \mathrm{~m}$ ). This part of the forest was dominated by old deciduous trees (e.g., Quercus spp.) and was bordered on one side by a grazed field. The distance of nest boxes from forest edge ranged from 5 to $60 \mathrm{~m}$ (median $20 \mathrm{~m}$ ). Breeding started synchronously in the colony, and most pairs reared a single brood in 1998 (only two new clutches were initiated after the first broods hatched). Carnus hemapterus was the dominant blood-sucking ectoparasite of nestlings in both years. Louse-flies (Ornithomyia avicularia) were also present on a few chicks (19 louse-flies were collected from 10 chicks in 1998). The chewing lice Brueelia nebulosa, Menacanthus eurysternus, Myrsidea cucullaris, and Sturnidoecus sturni were also observed on nestlings. Their prevalence did not exceed $40 \%$ (L. Rózsa, unpublished data) and they occurred mostly on full-grown, feathered nestlings.

Ectoparasites were collected from 140 nestlings (33 broods) between 12 and 24 May 1998. We did not collect flies from the remaining 9 nests because clutches were abandoned or freshly hatched chicks died before the start of the parasite survey. All broods included represented the first breeding attempts of the birds in that year. After chicks hatched, the broods were inspected at intervals of 2-7 days. The live nestlings were counted and weighed to the nearest $0.5 \mathrm{~g}$ at each visit. A sample of flies was collected from each brood on one of these visits, and a second sample was taken from 15 broods at a later date (so the other 18 broods were 
sampled only once during the study). The dates of first parasite collection varied between nests and were distributed over the nestling period (12-22 May; the body mass of nestlings varied from 10 to $70 \mathrm{~g}$ (median $47.1 \mathrm{~g}$ )). The second fly collection was made at the end of the nestling period (22-24 May). Nests to be inspected on a given date were chosen randomly, i.e., we chose a predetermined number of nests randomly from all available nests on each sampling date. For parasite inspections, the nest box was removed from the colony for the duration of sampling (ca. 10-30 min) and an empty nest box with the entrance closed was put in its place as a dummy to minimise the disturbance caused to parents and neighbouring pairs by the removal of nest boxes. Chicks were taken from the nest box singly, their body and plumage were examined visually for adult $C$. hemapterus, and all detected flies were collected. Flies were captured with forceps and an aspirator, either directly from the body of nestlings or from a white sheet placed below. We did not attempt to collect flies from the nest material. Captured flies were stored in $70 \%$ alcohol. During the fieldwork we adhered to Hungarian legal requirements and to the instructions given in Guidelines for the Use of Animals in Research (Association for the Study of Animal Behaviour and Animal Behavior Society 1997).

We used the first parasite samples for all analyses, except when the second samples from resampled broods were compared with the first samples of late-sampled broods (see below). From the stored samples we determined $(i)$ the total number of flies captured, (ii) the number of winged individuals, and (iii) the numbers of males and females. The shape of the abdomen and genitalia was checked under a binocular microscope to determine the sex of individuals. The average abundance of parasites in a brood (brood mean abundance) was calculated as the mean number of flies collected on individual nestlings within a brood, including parasitefree nestlings. The proportion of winged flies was expressed as the ratio of winged individuals to all adult flies collected in the nest. Sex ratio was calculated as the ratio of males to all adult flies collected in a nest. Spatial position of nests was quantified using four variables: (1) nearest neighbour distance, (2) mean distance from all active nests, (3) distance from the geometric centre of the colony, and (4) distance from forest edge. All variables were calculated from a detailed map of the colony. The daily growth rate (mean change in body mass over a period of 4-16 days (median 8 days)) was estimated for periods when nestling body mass was below $70 \mathrm{~g}$; we assumed approximately linear growth for this phase of nestling development (for example, see Feare 1984, p. 147). Periods of declining mass after mean brood body mass peaked were excluded. Observation of most broods started a few days after hatching, thus the exact date of hatching was unknown in these cases. Nestling body mass was used to quantify chick development in relation to changes in parasite load.

Aggregation statistics such as the index of discrepancy $(D)$ and the exponent of the negative binomial $(k)$ were calculated according to Poulin (1993) and Bliss and Fisher (1953), respectively. Since the distribution of most variables deviated from a normal distribution, we used non-parametric statistics throughout. The Bonferroni correction was used to adjust the significance level to $\alpha=0.05$ in multiple comparisons (Chandler 1995). Statistical tests were performed using SPSS 7.5 for Windows. The medians, lower quartile (LQ), upper quartile (UQ), and two-tailed probability are given.

\section{Results}

\section{Measures of $C$. hemapterus infection in broods}

In total, $2775 C$. hemapterus were collected from starling nestlings. Out of 33 broods, 31 were infected (94\% prevalence). In 18 broods all nestlings were parasitised. The total number of flies collected from a brood ranged from 0 to 284 and the median was 54.0 flies per brood (LQ = 5.0; UQ = 155.5; $n=33$ ). Among individual nestlings, the prevalence of flies was $69 \%(n=140)$. For individual nestlings, abundance ranged from 0 to 117 , with a median of 8.0 flies per bird $(\mathrm{LQ}=0, \mathrm{UQ}=33.8 ; n=140)$. The median of brood mean abundances was $17.2(\mathrm{LQ}=1.1, \mathrm{UQ}=32.9 ; n=33)$. The distribution of flies was aggregated both among broods (total number of flies per brood; $D=0.57, k=0.48, n=33$ ) and among individual nestlings (calculated for all nestlings pooled from all nests; $D=0.64, k=0.34, n=140$; Fig. 1).

One hundred and four winged flies were collected, and the median proportion of winged specimens per nest was 0.0035 (LQ $=0.00$, UQ $=0.0272 ; n=31$ broods). More females (70) than males (34) were winged, and more females were among the winged flies than expected from the sex ratio of the total sample ( $\chi^{2}$ test, $\chi^{2}=9.9$, df $=1, P=0.002$ ). Out of 2762 flies sexed, 1322 were males. The median sex ratio was 0.447 (LQ $=0.385, \mathrm{UQ}=0.512 ; n=31$ broods), and the proportion of female-biased parasite populations was higher than expected from a balanced sex ratio ( 9 broods were male-biased or balanced and 22 broods were femalebiased; binomial test, $P=0.031$ ).

Brood parasite burdens changed markedly during nestling development. Brood mean abundances increased from hatching to a peak at about 40-50 g nestling mass (corresponding to about 5-8 days of nestling age; Feare 1984) and decreased to low levels afterwards (Fig. 2). Both the proportion of winged forms and the proportion of male flies decreased with increasing mean body mass of nestlings (Spearman's rank correlation, proportion of winged flies: $r_{\mathrm{s}}=-0.640, P=$ 0.000; proportion of males: $r_{\mathrm{s}}=-0.370, P=0.040, n=31$ broods; Figs. 3 and 4).

Brood size was not related to brood mean abundance $\left(r_{\mathrm{s}}=\right.$ $-0.029, P=0.871, n=33)$, proportion of winged flies $\left(r_{\mathrm{s}}=\right.$ $0.199, P=0.282, n=31)$, or sex ratio of flies $\left(r_{\mathrm{s}}=0.181\right.$, $P=0.331, n=31$; brood size ranged from 2 to 6 nestlings). Brood size also was not related to the total number of flies found in the broods $\left(r_{\mathrm{s}}=0.105, P=0.560\right)$. Because $C$. hemapterus populations changed significantly during the growth of the nestlings (see above), we used residual parasite abundances, controlled for between-nest differences in development of young, to investigate the relationship between brood size and parasite burden. The residuals were taken from regressions between nestling body mass $(X)$ and the dependent variables $(Y)$. Variables were log-transformed before analysis. Residuals were obtained from equations of the best fitting regression models as measured by the highest $r^{2}$ value (abundance: $Y=-2.5+X+6.4 X^{2}-3.4 X^{3}, r^{2}=$ 0.758 , df $=30, P=0.000$; proportion of winged flies: $Y=$ $0.63+X+0.51 X^{2}-0.41 X^{3}, r^{2}=0.380$, df $=29, P=$ 0.001 ; sex ratio: $Y=0.17-0.14 X, r^{2}=0.128$, df $=29, P=$ 0.049 ; total number of flies per brood: $Y=-2.7+X+7.8 X^{2}$ $-3.7 X^{3}, r^{2}=0.736$, df $\left.=30, P=0.000\right)$. Brood size was not related, however, to residuals of brood mean abundance ( $\left.r_{\mathrm{s}}=-0.067, P=0.713, n=33\right)$, proportion of winged flies $\left(r_{\mathrm{s}}=0.248, P=0.179, n=31\right)$, fly sex ratio $\left(r_{\mathrm{s}}=0.135, P=\right.$ $0.468, n=31)$, or total number of flies per brood $\left(r_{\mathrm{s}}=0.050\right.$, $P=0.781, n=33)$.

Parasite removal at early and mid nestling stages did not alter parasite abundances measured at late nestling stages. 
Fig. 1. Frequency distribution of starling nestlings among Carnus hemapterus infection classes ( $n=140$ nestlings).

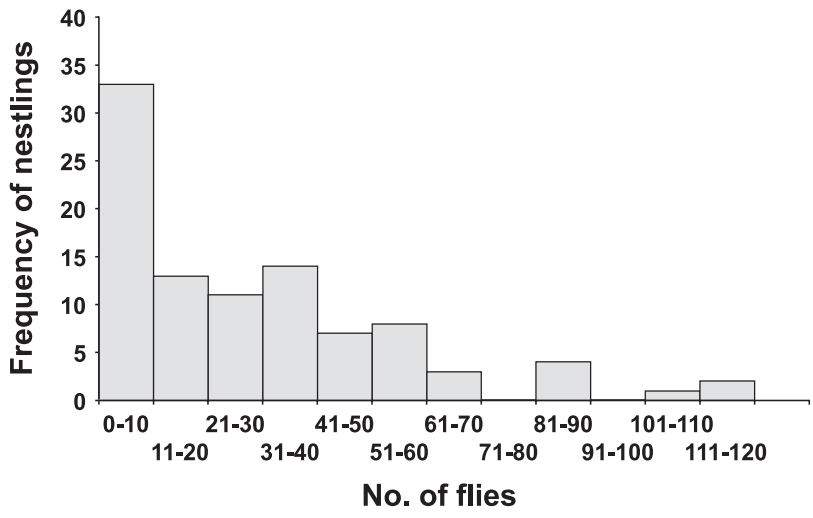

Fig. 3. Proportion of winged flies to all adult flies in starling broods in relation to the mean body mass of nestlings measured when parasites were collected ( $n=31$ broods).

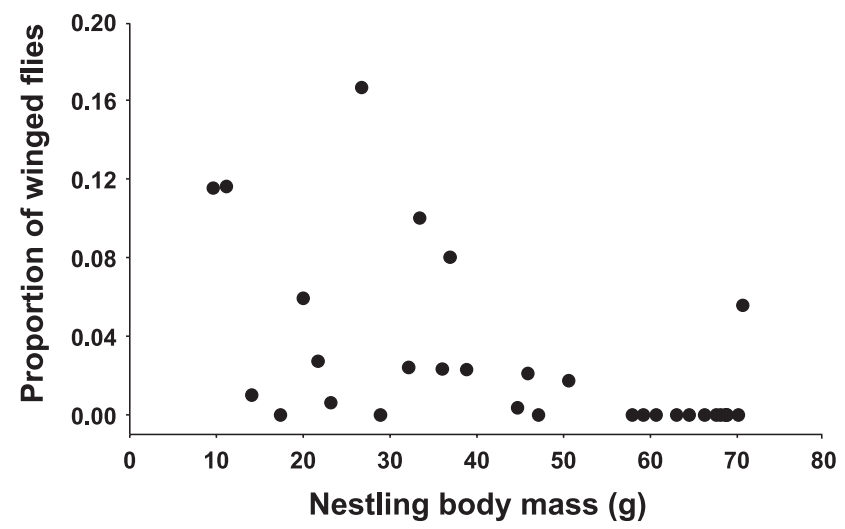

Fifteen broods sampled early in the study period (12-15 May; median body mass of nestlings $=32.1 \mathrm{~g}$ ) were resampled at the end of the study (22-24 May; median body mass of nestlings $=67.3 \mathrm{~g})$. Brood mean abundances in the second samples from these resampled broods (median $=1.3$ flies per nestling, $\mathrm{LQ}=0.5$, UQ $=2.3$ ) did not differ from the abundance of parasites found in broods that were sampled only at the end of the study period (22 May; median $=1.0$ flies per nestling, $\mathrm{LQ}=0.4$, UQ $=2.3$; Mann-Whitney $U$ test, $z=$ $0.312, P=0.775$; median body mass of nestlings $=67.6 \mathrm{~g}$, $n=15$ broods).

\section{Relationship between spatial position of the nest and parasite abundance}

We used residual parasite measures (see above) to investigate the potential effects of spatial position of nests on parasite burdens of nestlings. Residual brood mean abundances tended to decrease as closest neighbour distances increased, but the relationship was not significant at the corrected significance level (Table 1). Average distance from other nests and distance from the colony centre were not related to residuals of brood mean abundances, proportions of winged individuals, or sex ratios (Table 1). Similarly, neither of the measured parasite variables was related to the distance of nest boxes from forest edge (brood mean abundance: $r_{\mathrm{s}}=$ $-0.063, P=0.729, n=33$; proportion of winged flies: $r_{\mathrm{s}}=$
Fig. 2. Brood mean abundances of parasites (mean number of flies per nestling) in relation to the mean body mass of nestlings, measured when parasites were collected ( $n=33$ broods). The open arrowhead indicates the approximate time when feathers started to grow and the solid arrowhead indicates the time when the nestlings became covered with feathers.

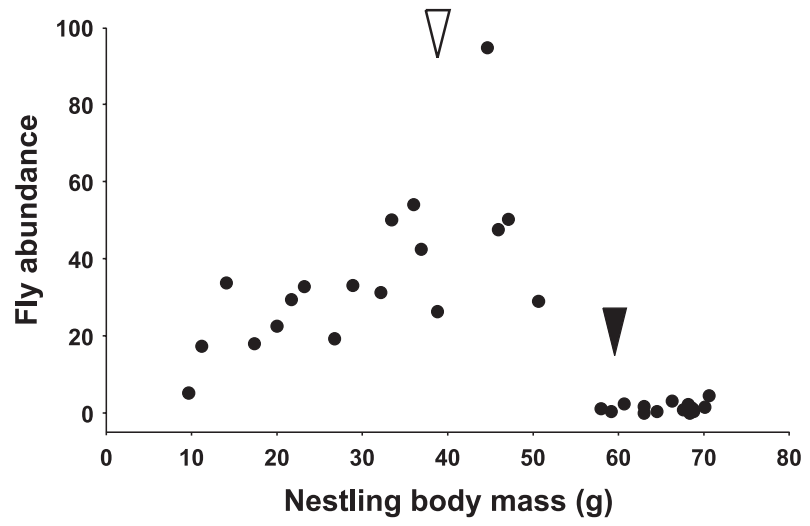

Fig. 4. Proportion of males to all adult flies on starling broods in relation to the mean body mass of nestlings measured when parasites were collected ( $n=31$ broods).

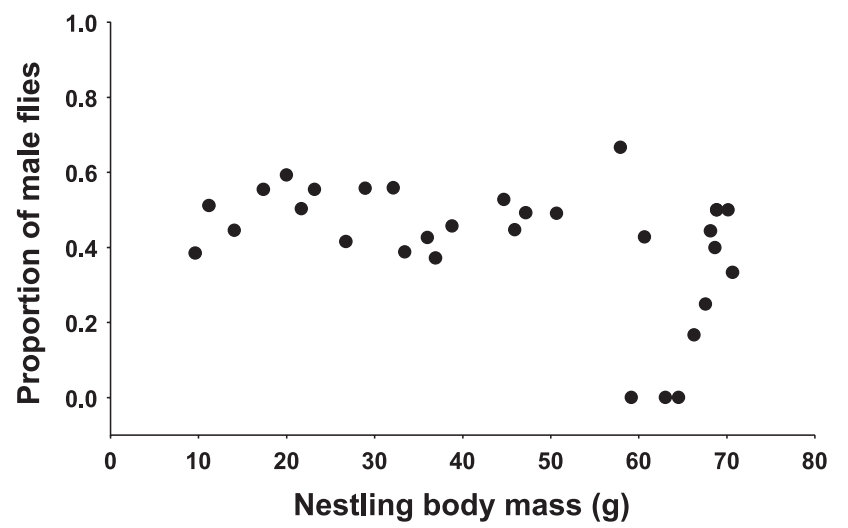

$-0.165, P=0.375, n=31$; sex ratio: $r_{\mathrm{s}}=-0.025, P=0.894$, $n=31)$.

Half of the broods were sampled at the late nestling stage, when parasite burdens were very low (Fig. 2). Because the low variability in parasite burden among these nests may have reduced the chance of detecting any effect of nest position, we reanalysed the data by excluding nests in which mean nestling body mass was larger than $50 \mathrm{~g}$ (an arbitrary limit chosen to eliminate all nests with markedly reduced infections; Fig 2). We recalculated residuals for parasite abundance, ratio of winged flies, and sex ratio using this subsample of nests, as explained above (equations not shown). However, restricting the analyses to the early nestling stage did not change our results. Residual parasite measures were not related to either within-colony position of nests $\left(r_{\mathrm{s}}=0.047-\right.$ $0.363, P=0.152-0.859, n=17$ broods) or distance from forest edge ( $r_{\mathrm{s}}=0.012-0.061, P=0.816-0.924, n=17$ broods).

\section{Nestling growth and mortality}

The mean of nestlings' daily growth rates per brood was not related to residual brood mean abundances, when the latter variable is expressed as residuals from a regression be- 
Table 1. Correlations between characteristics of Carnus hemapterus populations and the spatial position of starling nests.

\begin{tabular}{llll}
\hline Distance from: & $\begin{array}{l}\text { Brood mean } \\
\text { abundance }(n=33)\end{array}$ & $\begin{array}{l}\text { Proportion of winged } \\
\text { flies }(n=31)\end{array}$ & $\begin{array}{l}\text { Sex ratio } \\
(n=31)\end{array}$ \\
\hline closest neighbour & & & 0.058 \\
$\quad r_{\mathrm{s}}$ & -0.361 & 0.178 & 0.775 \\
$P$ & 0.039 & 0.339 & 0.241 \\
all active nests & & & 0.191 \\
$\quad r_{\mathrm{s}}$ & -0.116 & 0.164 & \\
$P$ & 0.519 & 0.377 & 0.219 \\
centre of the colony & & & 0.236 \\
$\quad r_{\mathrm{s}}$ & -0.112 & 0.176 & 0.370 \\
$P$ & 0.536 & 0.370 & \\
\hline
\end{tabular}

Note: Coefficients of Spearman's rank correlations and their uncorrected $P$ values are given. The Bonferroni correction was used to adjust the significance level for 9 post-hoc comparisons, and $\alpha(k=9)=0.0057$ was used as a critical level of significance (Motulsky 1995). None of the correlations was significant at the adjusted significance ( $n$ is the number of broods; ratios were not calculated for two broods without parasites).

tween body masses and brood abundances (see above; $r_{\mathrm{s}}=$ $0.262, P=0.170, n=29$ broods). In total, 34 dead nestlings were found in 17 nests during our study. Mortality (the proportion of dead nestlings in broods) was not related to residual brood mean abundance of $C$. hemapterus $\left(r_{\mathrm{s}}=-0.152\right.$, $P=0.400, n=33$ broods). Also, no difference was found in residual brood mean abundances between nests with or without observed mortality (median $=-0.07, \mathrm{LQ}=-0.2$, UQ $=$ 0.2 , and median $=-0.02, \mathrm{LQ}=-0.3, \mathrm{UQ}=0.3(n=17$ and 16, respectively); Mann-Whitney $U$ test, $z=0.324, P=$ 0.746). The exclusion of broods with mean nestling mass above $50 \mathrm{~g}$ did not change these results qualitatively (not shown).

\section{Discussion}

We observed a relatively high prevalence and abundance of $C$. hemapterus on developing chicks. Carnus hemapterus was also the dominant blood-sucking ectoparasite of nestlings in the starling colony studied. Peak abundances were observed on nestlings at an intermediate developmental stage, about 5-8 days of age, before the emergence of plumage. This pattern is similar to those reported for starlings (Walter and Hudde 1987) and other bird species (e.g., American kestrel, Dawson and Bortolotti 1997; barn owl, Roulin 1998). It is not clear why feathered chicks are abandoned by the flies. The decline is probably not related to a reduction in fecundity of flies because the number of eggs laid by individual females does not change during the development of nestlings (Roulin 1999). Perhaps feathers inhibit effective foraging, or the stronger immune response of older nestlings increases fly mortality (Roulin 1998). Despite our current inability to determine the proximate causes of population changes, $C$. hemapterus has qualitatively similar patterns of population dynamics on different host species, with rapidly increasing numbers on small chicks and a similarly rapid decline after the feathers start to grow. However, the population dynamics of this fly clearly differ among avian hosts in one important respect: a shorter period of parasite activity is observed on hosts characterised by a shorter nestlingdevelopment period. Further research could test whether variation in the length of the nestling period is associated with adaptive variation in the reproductive behaviour of flies inhabiting different host species.

The proportion of winged flies and the proportion of males decreased during the development of chicks. A similar decrease in the number of winged adults was reported from a detailed study of the barn owl $-C$. hemapterus system (Roulin 1998). These patterns may be explained by several mechanisms. For example, winged flies may become scarce simply because fewer newly emerged winged individuals are present in the population at later than at earlier stages of nestling development. Alternatively, dispersive forms of flies may abandon feathered nestlings sooner than young nestlings in order to find more suitable hosts, or flies on large nestlings may lose their wings sooner to facilitate movement among the feathers of the chicks. Without more detailed knowledge about the reproductive and dispersive behaviour of $C$. hemapterus, however, it is difficult to evaluate which of these explanations is relevant.

Roulin (1998) reported that experimental brood-size manipulation affected the total $C$. hemapterus population on barn owl broods (larger broods had more parasites), but not parasite abundance on individual nestlings. He concluded that nestling condition did not affect the abundance of flies, and parasite burden was probably limited by competitive interactions among individuals living on the same nestling. A similar pattern was found in American kestrels, where abundance of $C$. hemapterus on individual nestlings was unrelated to brood size (but prevalence was higher in larger broods; Dawson and Bortolotti 1997). Our results are consistent with those of the above studies in that brood mean abundance was unrelated to brood size, which supports the idea that competitive interactions among flies may determine their population size. It is not clear, however, why total parasite number was unrelated to brood size in our study.

We found that parasite removal at early and mid nestling stages did not alter parasite abundances measured at late nestling stages. This finding, together with the observation that flies appeared in the nest boxes soon after hatching in both years, suggests that the mobility and colonising ability of $C$. hemapterus are high. We do not know, however, whether the reappearing adult flies in the second samples from resampled starling nests came from outside the nest boxes or 
were recruited from the larvae and pupae developing in the nest material. Because we did not collect larvae and adults from the nest material, individuals from this source could be involved in restoring fly populations after parasite removal. Detailed monitoring of population sizes following parasite removal would be useful for evaluating the significance of immigration in the reestablishment of $C$. hemapterus populations.

We found no convincing evidence of a relationships between within-colony spatial position of nests and parasite burden of nestlings. Although residual brood mean abundances tended to decrease as closest neighbour distances increased, this relationship was not significant and brood mean abundance was not related to other measures of spatial position. Furthermore, the other parasite variables (proportion of winged adults, sex ratio) were also not related to any of the studied variables describing relative spatial position of nests. Thus, the distribution of $C$. hemapterus appears to be unaffected by nest density of hosts, at least at the spatial scale investigated in our starling colony. Because winged flies may be able both to move easily between nests and locate broods effectively by means of some sensory cue, the spatial differences in nest density may not have important effects on variation in migrating fly density within this small starling colony.

Finally, we found no correlational evidence of fitness loss associated with the high abundances of $C$. hemapterus. These results agree with those of other studies in which parasitism by $C$. hemapterus was investigated (Grimaldi 1997). In only 1 out of 4 studies was a reduction in reproductive success caused by $C$. hemapterus detected (starling, Walter and Hudde 1987; barn owl, Kirkpatrick and Colvin 1989; American kestrel, Dawson and Bortolotti 1997; only Cannings (1986) found an effect in the northern saw-whet owl, Aegolius acadicus). Dawson and Bortolotti (1997) suggested that C. hemapterus prefers to parasitise larger American kestrel nestlings, which may account for the lack of adverse effects of parasitism on nestling condition in that species. Bodymass differences may affect levels of parasitism, while differences in parasitism levels may also affect body mass and development. Evidently, correlational studies cannot be used to investigate the direction of causalities in biological systems, which emphasises the importance of experimental studies.

In conclusion, we found high prevalences and abundances of $C$. hemapterus on nestlings of colonially breeding starlings. The abundance of parasites was related to nestling development but not to spatial position of nests. Correlative evidence did not indicate that increased infection would lead to a decrease in growth rate or survival of nestlings.

\section{Acknowledgements}

We thank L. Papp for his advice and help in identifying and sexing $C$. hemapterus, and A. Roulin and B. Walther for their comments on a previous version of the manuscript. The Experimental Station of the Szent István University provided housing and logistic help during the fieldwork, and numerous graduate students assisted in the work with nest boxes and starling nestlings. Z. Barta implemented the algorithms we used for calculating spatial-position data. The study was supported in part by a research grant from Szent István Uni- versity (NKB-1999-KUT). A.L. was supported by a Bólyai János Research Fellowship and L.R. was supported by a Széchenyi Professorship during the preparation of the manuscript.

\section{References}

Association for the Study of Animal Behaviour and Animal Behavior Society. 1997. Guidelines for the use of animals in teaching and research. Academic Press, London.

Bliss, C.I., and Fisher, R.A. 1953. Fitting the negative binomial distribution to biological data. Biometrics, 9: 176-200.

Brown, C.R., and Brown, M.B. 1996. Coloniality in the cliff swallow: the effect of group size on social behavior. University of Chicago Press, Chicago.

Cannings, R.J. 1986. Infestations of Carnus hemapterus Nitzsch (Diptera: Carnidae) in northern saw-whet owl nests. Murrelet, 67: $83-84$.

Capelle, K.J., and Whitworth, T.L. 1973. The distribution and avian hosts of Carnus hemapterus (Diptera: Milichiidae) in North America. J. Med. Entomol. 10: 526-527.

Chandler, C.R. 1995. Practical considerations in the use of simultaneous inference for multiple tests. Anim. Behav. 49: 524-527.

Clarck, F., and McNeil, D.A.C. 1981. The variation in population densities of fleas in house martin nests in Leicestershire. Ecol. Entomol. 6: 379-386.

Cramp, S., and Perrins, C.M. 1994. The birds of the western Palearctic. Vol. VIII. Oxford University Press, Oxford.

Davis, J.A., and Brown, C.R. 1999. Costs of coloniality and the effect of colony size on reproductive success in purple martins. Condor, 101: 737-745.

Dawson, R.D., and Bortolotti, G.R. 1997. Ecology of parasitism of nestling American kestrels by Carnus hemapterus (Diptera: Carnidae). Can. J. Zool. 75: 2021-2026.

Duffy, D.C. 1983. The ecology of tick parasitism on densely nesting Peruvian seabirds. Ecology, 64: 110-119.

Feare, C. 1984. The starling. Oxford University Press, Oxford.

Grimaldi, D. 1997. The bird flies, genus Carnus: species revision, generic relationships, and fossil Meoneura in amber (Diptera: Carnidae). Am. Mus. Novit. No. 3190. pp. 1-30.

Hamilton, W.D. 1967. Extraordinary sex ratios. Science (Washington, D.C.), 156: 477-488.

Hoi, H., Darolova, A., König, C., and Kristofik, J. 1998. The relation between colony size, breeding density and ectoparasite loads of adult European bee-eaters (Merops apiaster). Ecoscience, 5: $156-163$.

Hoogland, J.L., and Sherman, P.W. 1976. Advantages and disadvantages of bank swallow (Riparia riparia) coloniality. Ecol. Monogr. 46: 33-58.

Kirkpatrick, C.E., and Colvin, B.A. 1989. Ectoparasitic fly Carnus hemapterus (Diptera: Carnidae) in a nesting population of common barn-owls (Strigiformes: Tytonidae). J. Med. Entomol. 26: $109-112$.

Lehmann, T. 1993. Ectoparasites: direct impact on host fitness. Parasitol. Today, 9: 8-13.

Loye, J., and Carroll, S. 1995. Birds, bugs and blood: avian parasitism and conservation. Trends Ecol. Evol. 10: 232-235.

Motulsky, H. 1995. Intuitive biostatistics. Oxford University Press, Oxford.

Møller, A.P. 1987. Advantages and disadvantages of coloniality in the swallow Hirundo rustica. Anim. Behav. 35: 819-832.

Møller, A.P. 1993. Ectoparasites increase the cost of reproduction in their hosts. J. Anim. Ecol. 62: 309-322. 
Møller, A.P., Dufva, R., and Allander, K. 1993. Parasites and the evolution of host social behavior. Adv. Study Behav. 22: 65-102.

Papp, L. 1998. Family Carnidae. In Contributions to a manual of Palearctic Diptera. Vol. III. Edited by L. Papp and B. Darvas. Science Herald, Budapest. pp. 211-217.

Poulin, R. 1993. The disparity between observed and uniform distributions: a new look at parasite aggregation. Int. J. Parasitol. 23: 937-944.
Roulin, A. 1998. Cycle de reproduction et abondance du diptère parasite Carnus hemapterus dans les nichées de chouettes effraies Tyto alba. Alauda, 66: 265-272.

Roulin, A. 1999. Fecondite de la mouche Carnus hemapterus ectoparasite des jeunes chouettes effraies Tyto alba. Alauda, 67: 205-212.

Walter, G., and Hudde, H. 1987. Carnus hemapterus (Milichiidae, Diptera), an ectoparasite of nestlings. J. Ornithol. 128: 251-255. 